\title{
Fundamentos e processos da formação continuada na rede municipal de Goiânia
}

\author{
Fundamentals and processes of continuing educationin the Goiânia municipal \\ network \\ Fundamentos y procesos de formación continua en la red municipal de Goiânia
}

SARAH RIZZIA CAMPOS LUIZ

Orcid Id: https://orcid.org/0000-0002-9666-0761

Universidade Federal De Goiás

LÚCIA MARIA ASSIS

Orcid Id: http://orcid.org/0000-000263802129

Universidade Federal De Goiás

\begin{abstract}
Resumo: Este artigo é resultado de uma pesquisa realizada no ano de 2019 e teve como objetivo apresentar os fundamentos teóricos e metodológicos da formação continuada dos professores na Gerência de Formação dos Profissionais da SME (GERFOR). A pesquisa teve como metodologia o levantamento bibliográfico e documental, fundamentada em Janela (2000), Saviani (2008), Dias Sobrinho (2003), Luckesi (2010), Libâneo (2015), Guimarães (2004), entre outros. Concluiu-se que tendo em vista que as políticas para formação continuada abrangem cursos de curta ou longa duração, que objetivam promover a atualização, desenvolvimento e aprofundamento profissional constante dos profissionais docente, que busquem atender as necessidades recorrentes da prática educacional, bem como acompanhar o desenvolvimento da legislação educacional e promover a atualização permanente dos conhecimentos e saberes da docência, a GERFOR tem atuado nesse sentido, de modo a subsidiar as melhorias das práticas dentro do ambiente escolar.
\end{abstract}

Palavras-chave: Formação de professores e políticas públicas; Formação de professores e avaliações externas; Formação de professores e avaliação.

Abstract: This article is the result of a survey carried out in 2019 and aimed to present
the theoretical and methodological foundations of continuing teacher training in the SME
Professional Training Management (GERFOR). The research had as methodology
bibliographic survey, documentary research, and empirical stage, with the application of
questionnaires - for the coordination of GERFOR and the students. The research had as
theoretical basis Janela (2000), Saviani (2008), Dias Sobrinho (2003), Luckesi (2010),
Libaneo (2015), Guimaräes (2004), among others. It was concluded that GERFOR plans
its courses based on the demands raised by managers and teachers of the network contemplating
aspects related to large-scale evaluations (national IDEB and other tests applied at the state
and municipal levels). the main contents required in the exam of the Brazil Exam (Portuguese
and Mathematics).

Keywords: Teacher training and public policies; Teacher training and external evaluation; Teacher training and evaluation. 


\begin{abstract}
Resumen: Este articulo es el resultado de una investigación realizada en 2019 con el objetivo de presentar los fundamentos teóricos y metodológicos de la formación continua del profesorado en Gestión de la Formación Profesional de la SME (GERFOR). La investigación tuvo como metodología la encuesta bibliográfica, la investigación documental y la etapa empírica, con aplicación de cuestionarios para la coordinación de GERFOR y los estudiantes. La investigación tuvo como base teórica Janela (2000), Saviani (2008), Dias Sobrinho (2003), Luckesi (2010), Libâneo (2015), Guimarães (2004), entre otros. Se concluyó que GERFOR planifica sus cursos en función de las demandas planteadas por los gerentes y maestros de la red contemplando aspectos relacionados con evaluaciones a gran escala (IDEB nacional y otras pruebas aplicadas a nivel estatal y municipal). Los principales contenidos requeridos en el examen del Examen de Brasil (Portugués y Matemáticas).
\end{abstract}

Palabras clave: Formación docente y políticas públicas; Formación del profesorado y evaluación externa; Formación y evaluación del profesorado.

\title{
INTRODUÇÃO
}

Este estudo apresenta parte dos resultados de uma pesquisa realizada no Programa de Pós-Graduação em Educação (PPGE), da Faculdade de Educação (FE) da Universidade Federal de Goiás (UFG), na linha de pesquisa Estado, Políticas e História da Educação, e situa-se no campo de estudos das políticas públicas educacionais relativas à formação e valorização docente.

O estudo da Gerência de Formação dos Profissionais da SME fundamentase no princípio de que a formação docente se constitui como algo permanente, sendo constitutiva e constituinte da profissionalidade docente (GUIMARÃES, 2006), refere-se aos aspectos de atuação do professor e é inerente ao trabalho político-pedagógico-didático.

Nesse sentido, Chimentão (2009, p. 3) considera que a formação continuada deve ser vista "como processo permanente de aperfeiçoamento dos saberes necessários à atividade profissional, realizado após a formação inicial, com o objetivo de assegurar um ensino de melhor qualidade dos educandos".

Dentre os diversos modos de formação continuada vigentes no Brasil, destacam-se os cursos de extensão e de aprimoramento que podem ter carga horária variada de acordo com a sua proposta e os seus objetivos, em geral realizados em menor tempo. Os cursos de especialização Lato Sensu, por sua vez, exigem carga horária mínima de 360 horas, enquanto na pós-graduação Stricto Sensu é conferido o diploma de mestre/doutor. Destaca-se que o atual Plano Nacional de Educação (PNE), Lei 13.005 (BRASIL, 2014) prevê, em sua Meta 16, “formar, em nível de pós-graduação, cinquenta por cento dos professores da educação básica, até o último ano de vigência deste PNE, e garantir a todos os profissionais da educação básica formação continuada em sua área de atuação, 
considerando as necessidades, demandas e contextualizações dos sistemas de ensino." Portanto, nota-se que a formação continuada de professores é colocada como política de Estado no PNE em vigor.

As políticas de formação continuada ganharam um maior protagonismo a partir da década de 1990, quando as questões relativas à melhoria da qualidade da educação básica passaram a ser prioridade na Reforma do Estado brasileiro, promovida pelo governo de Fernando Henrique Cardoso (1995-1998 e 19992002). Nesse contexto, melhorar a qualidade significava melhorar o desempenho dos estudantes e, para isso, foram implementadas as primeiras políticas de avaliação em larga escala no Brasil, após a experiência ser considerada exitosa no estado de São Paulo.

De acordo com Gatti (2013), a partir de 1993, o MEC, juntamente com as Secretarias Estaduais de Educação, implementou o Sistema de Avaliação da Educação Básica (SAEB), que tinha como base uma amostra nacional de alunos, abrangendo séries do ensino fundamental e médio, inicialmente com provas objetivas do modelo clássico e aplicação de questionários informativos sobre alunos e escolas. A intenção era "prover informações para tomadas de decisão quanto a diversos aspectos das políticas educacionais, bem como para pesquisas e discussões, a partir da geração e organização de informações sobre o desempenho acadêmico dos alunos nos sistemas e de fatores a eles associados" (GATTI, 2013, p. 56).

Segundo a autora, o SAEB possuía dois grandes eixos: o primeiro visava o acesso ao ensino básico, a demanda e a eficiência; o segundo tratava da qualidade, considerando quatro dimensões: o produto, o contexto, o processo e os insumos. Os instrumentos para coleta de dados eram as provas dos alunos, questionários para os alunos, professores e diretores, e questionários sobre as condições da escola.

Atuando como consultora do governo Fernando Henrique Cardoso (FHC), Gatti destaca que, em 1995, após discussões de pesquisadores da Fundação Carlos Chagas (FCC) com a presidência do INEP/MEC e com o então ministro da Educação Paulo Renato de Souza, a metodologia desse sistema foi alterada e adotou-se a Teoria de Resposta ao Item (TRI). Essa mudança foi feita por acreditar que a "metodologia poderia oferecer, com suas escalas, melhores condições de comparabilidade dos resultados" (GATTI, 2013, p. 57). Naquele momento, a avaliação deveria cumprir uma função diagnóstica. No final da década de 1990, em acréscimo, 
agregaram-se ao modelo geral de avaliação estudos de caso de situações específicas consideradas relevantes para análise mais aprofundada de fatores contextuais intervenientes nos resultados. Conhecimentos importantes foram levantados sobre a interrelação de fatores no cotidiano escolar que favoreciam bons desempenhos de alunos em condições contextuais díspares (p. 57).

Ainda de acordo com a autora, posteriormente, em 2007, o MEC expandiu a avaliação de desempenho do sistema educacional, com a Prova Brasil, aplicada a todos os alunos dos primeiros anos do ensino fundamental, integrando essa prova ao SAEB, possibilitando avançar na construção de um indicador, o Índice de Desenvolvimento da Educação Básica (IDEB), composto de dados a partir do fluxo escolar e das médias de desempenho nas avaliações nacionais. Essas médias referem-se ao desempenho no SAEB para os estados e na Prova Brasil para os municípios (GATTI, 2013, p. 57).

Freitas (2013), porém, mostra que a publicação dos resultados do IDEB acabou estimulando comportamentos destinados à comparação, competição, premiação e punição, distanciando-o do seu objetivo inicial de contribuir para melhorar a qualidade do ensino de forma socialmente referenciada. Os processos de avaliação em larga escala tornaram-se centrais na definição das políticas educacionais, influenciando na definição dos currículos ao induzir os conteúdos para o que preveem as matrizes de referência dos exames e dos aportes de recursos para as redes e escolas, que passaram a balizar as políticas de premiação a docentes e gestores que obtivessem os melhores resultados, o que acabou estimulando gestores a selecionarem os alunos com melhor desempenho para fazer a prova, forçando artificialmente um bom resultado no ranking (ASSIS e AMARAL, 2013).

Tendo em vista esses e outros eventos que mostram os problemas relacionados à grande centralidade dos resultados das avaliações em larga escala, buscou-se, com este estudo, responder a seguinte questão: como ocorre a formação continuada dos professores na Gerência de Formação dos Profissionais da SME (GERFOR) e em que medida os exames nacionais em larga escala têm influenciado essa formação?

Elegeu-se como objetivos específicos: a) analisar as políticas públicas que têm subsidiado a formação continuada de professores no Brasil entre os anos de 2008 a 2016; b) analisar qual é a concepção sobre formação inicial e continuada de professores expressas nessas políticas; c) caracterizar a Gerência de Formação dos Profissionais da SME; d) identificar os fundamentos teóricos e metodológicos que sustentam a formação continuada dos professores na Gerência de formação dos Profissionais da SME; e) analisar o histórico da Gerência de formação dos 
Profissionais da SME; f) Identificar e analisar as possíveis relações entre os resultados dos exames em larga escala (IDEB) e os processos de formação da GERFOR.

Do ponto de vista metodológico, esta pesquisa foi desenvolvida com base nos princípios da abordagem qualitativa de pesquisa, consistindo em um estudo de caso no qual se apresentam os fundamentos teóricos e normativos da formação continuada da rede municipal de Goiânia.

Como recorte temporal, elegeu-se os anos de 2008 e 2016, período de implantação do IDEB, que, segundo o Ministério da Educação (2016), foi criado em 2007, pelo Instituto Nacional de Estudos e Pesquisas Educacionais Anísio Teixeira (Inep), com o "objetivo de medir a qualidade do aprendizado nacional e estabelecer metas para a melhoria do ensino" (p. 1). Os testes para a formulação do IDEB foram aplicados nos quinto e nono anos do Ensino Fundamental, em que os estudantes respondem questões de Língua Portuguesa (focadas em leitura) e Matemática (com foco em resolução de problemas). O índice, que divulga resultados no período de dois em dois anos, conta também com respostas a um questionário socioeconômico, em que os estudantes informam fatores que podem influenciar o desempenho, assim como questionários para coletas de dados demográficos, perfil profissional e as condições de trabalho, respondidos por professores e diretores das turmas avaliadas.. Definiu-se o limite de 2016 por marcar o fim de um ciclo da política ${ }^{1}$ (2003-2010 - dois mandatos do presidente Lula, e 2011-2016 - um mandato e meio da presidenta Dilma) em que o Brasil foi governado por um partido político popular, mais alinhado às pautas sociais progressistas de perspectiva socialdemocrata (SOUZA, 2017).

\section{FORMAÇÃO CONTINUADA PARA O PROFISSIONAL DOCENTE}

No que tange à formação continuada de professores no Brasil, Andaló (1995) afirma que essas iniciativas começaram a ganhar força nos anos 1960, quando o INEP, juntamente com a direção dos Cursos de Aperfeiçoamento do Instituto de Educação do Rio de Janeiro, promoveram estudos sobre o

\footnotetext{
1 Em agosto de 2016, a presidenta eleita pelo Partido dos Trabalhadores para o seu segundo mandato, Dilma Rousseff sofreu um impeachment. No entanto, de acordo com Assis e Lima (2018), "está claro para parte significativa da sociedade brasileira que o impedimento de Dilma Rousseff, em 2016 caracterizou-se como um golpe, pois não teve relação com "crime de responsabilidade" tampouco com desvios de dinheiro público ou corrupção, mas com a interrupção de um projeto de Estado que vinha sendo construído desde a eleição do presidente Lula, em 2002, que passou a incluir os pobres no orçamento, a investir mais recursos públicos em educação e a priorizar a criação e ampliação de políticas de cunho social, com vistas à redução da pobreza e da histórica desigualdade social brasileira" (p.1). A esse respeito recomenda-se também: SOUZA, Jessé. A elite do atraso. Rio de Janeiro: LeYa, 2017; BOURDIEU, Pierre. A distinção: crítica social do julgamento. Porto Alegre: Zouk, 2011.
} 
aperfeiçoamento docente e passaram a questionar os objetivos dos cursos que eram oferecidos, com a intenção de aprimorar aquela formação.

Nesse sentido, Silva e Frade (1997) afirmam que, nas últimas três décadas do século $\mathrm{XX}$, no Brasil, houve três momentos políticos que influenciaram significativamente a formação continuada de professores, que são: a ditatura militar (1964-1985), o movimento de democratização da sociedade (1985) e os movimentos de mundialização da cultura e da economia (a partir do século XXI). Para tanto, buscou-se entender a importância da formação continuada de professores com o intuito de atender às demandas específicas que emergiam no cotidiano da escola, objetivando a garantia de um aprendizado permanente, voltado para a política da prática docente (SILVA e FRADE, 1997). Ribas (2000) afirma que, nos anos 1980, os programas de formação continuada oferecidos pelo governo e destinados a professores da rede pública tinham surtido pouco efeito, pois as propostas eram descontínuas e não atendiam às necessidades das escolas e dos professores.

A década de 1990 vem arraigada de novas questões, tais como a mundialização da cultura e a globalização da economia, o desenvolvimento tecnológico, dentre outros, que passaram a exigir dos docentes posicionamentos relacionados a essa demanda, novos procedimentos de estudo e trabalhos docente. Esse período se destaca também pela exigência de que as universidades devem ser as principais responsáveis pela formação inicial e continuada de professores (ALFERES e MAINARDES, 2011).

Portanto, Silva e Frade (1997) afirmam que, mesmo com a importante presença da universidade na formação de professores, a falta de qualidade na formação que é oferecida seria reflexo da desvinculação das teorias educacionais abordadas pelos currículos dos cursos de formação dos licenciados com a realidade dentro da escola, os problemas que ali são enfrentados diariamente, pois a universidade, por vezes, considera desnecessário tratar das necessidades das escolas em processos de formação e reflexão.

Silva e Frade (1997) nos mostram ainda que, no início da década de 1990, começou a ser enfatizada a formação do professor em serviço, aquela que acontece dentro da instituição de ensino, tais como oficinas, palestras, dentre outras modalidades, com a justificativa de que os pacotes de treinamento e encontros dos quais os professores participavam até então não estavam sendo suficientes para a melhoria da qualidade do ensino, fazendo-se necessário a participação dos professores de forma ativa na construção do saber. Propunha-se, então, uma formação continuada em seu local de trabalho, por meio de reflexão contínua sobre a prática dentro da escola. 
Assim, a partir da década de 1990, as políticas passaram a considerar o professor como destaque, por considerar que esse profissional foi inserido no debate educacional. Porém, a formação destinada a ele sofreu consequências, tais como o aligeiramento, a fragmentação e a diminuição de conteúdos.

Soares (2008) acredita que essa fragmentação e aligeiramento curricular ocorreu devido à agregação da reflexão da prática dos professores às tendências que passaram a formular os currículos a partir da definição de "competências", cuja formação prioriza um profissional tecnicamente competente, porém inoperante, disciplinado e adaptado, no que tange à política, pois

[...] na medida em que são fragilizados, precarizados, aligeirados e esvaziados de conteúdo os processos de trabalho e formação dos professores, em especial daqueles que atuam ou irão atuar na escola pública, há uma crescente e gradativa desqualificação desses profissionais e, por sua vez, o enfraquecimento da possibilidade da escola estar, de alguma forma, contribuindo para o fortalecimento de um projeto contra hegemônico de sociedade (p. 140).

Na mesma linha de análise, Gatti (2008) acredita que a proposta da formação continuada deve ser a de contribuir para a melhoria do ensino e diminuir o fracasso escolar, e afirma que os programas de formação continuada ainda não conseguiram atingir os objetivos propostos, por não compreenderem essa tarefa como sendo complexa, componente de um sistema educacional democrático, não seletivo e nem excludente, que isoladamente não atingirá mudanças significativas.

Autores como Pimenta e Ghedin (2002), Freire (2001) e Alonso (1999) afirmam que a prática reflexiva é a orientação fundamental para a formação continuada e, nesse sentido, deixam de entender a formação continuada do docente como simples processo de atualização - que, por vezes, pode ter ligação com o contexto em que o professor atua -, mas consideram que o fator principal é a construção de conhecimentos e teorias sobre a sua própria prática docente, por meio da reflexão crítica.

No artigo 67 da Lei de Diretrizes e Bases da Educação Nacional (LDBEN), lei no. 9.394 (BRASIL, 1996), é estipulado aos sistemas de ensino o dever de promover a valorização do profissional que busca essa formação e, no seu inciso II, a referida lei prevê o aperfeiçoamento como obrigação dos poderes públicos, assim como a concessão de licença temporária remunerada para esse objetivo. Baseado nesse Artigo, o município e Goiânia tem cumprido o papel de oferecer aos servidores da Rede Municipal a formação continuada em exercício da profissão, além de contar com a possibilidade de autorizar licenças remuneradas para a realização de formações Stricto Sensu. 
Para autores como Nóvoa (1991) e Veiga (1998), as ações relacionadas à educação continuada no Brasil só foram intensificadas nas últimas décadas do século XX, em meados da década de 1980, mas apenas na década seguinte (anos 1990) foi considerada como uma das possibilidades para construção de um novo perfil do professor.

A Rede Nacional de Formação Continuada de Professores da Educação Básica² (BRASIL, 2005) estabelece que "a formação do educador deve ser permanente e não apenas pontual, [pois] a formação continuada não é correção de um curso por ventura precário, mas necessária para a reflexão permanente do professor" (p. 5) (acréscimos nosso), buscando sempre a melhoria na qualidade do ensino ofertado pela educação pública.

Assim, o Conselho Nacional de Educação (CNE), em sua resolução de No 2 (BRASIL, 2015), de 1 de julho de 2015, formaliza as Diretrizes Curriculares Nacionais para a formação inicial em nível superior, bem como a formação continuada. O artigo 16, do capítulo VI, intitulado "Da formação continuada dos profissionais do magistério", descreve que

a formação continuada compreende dimensões coletivas, organizacionais e profissionais, bem como o repensar do processo pedagógico, dos saberes e valores, e envolve atividades de extensão, grupos de estudos, reuniões pedagógicas, cursos, programas e ações para além da formação mínima exigida ao exercício do magistério na educação básica, tendo como principal finalidade a reflexão sobre a prática educacional e a busca de aperfeiçoamento técnico, pedagógico, ético e político do profissional docente (BRASIL, 2015, p. 13).

O documento também prevê que a formação continuada compreende todas as atividades que abordam aspectos relacionados à atuação do profissional, que permitam refletir sobre suas práticas e objetivem reformular ações no exercício da profissão.

O artigo 17 das Diretrizes Curriculares Nacionais (DCN; BRASIL, 2015), orienta que a formação continuada deve ser pautada na oferta de atividades que busquem a formação docente, além de cursos de atualização, extensão, aperfeiçoamento, especialização, mestrado e doutorado que agreguem novos saberes e práticas, articulados às políticas e gestão da educação, à área de atuação do profissional e às instituições de educação básica, em suas diferentes etapas e modalidades da educação (p. 14).

2 Criada em 2004, objetivando a contribuição para a melhoria da qualidade da formação dos professores e alunos. Essa rede tem como público alvo os professores de educação básica da rede pública de ensino. 
Nesse sentido, Imbernón (2001) afirma que a escolha da formação deveria ser pautada na análise que cada um faz sobre sua própria prática docente, ou seja, "um processo constante de autoavaliação que oriente seu trabalho. A orientação para esse processo de reflexão exige uma proposta crítica da intervenção educativa, uma análise da prática do ponto de vista dos pressupostos ideológicos e comportamentais subjacentes." (p. 48-49).

Em consonância, Gatti (2013) afirma que, desde o fim do século XX e início do XXI, começaram as iniciativas para a formação continuada, muitas vezes com programas de caráter compensatório, que procuravam suprir os déficits de uma suposta má formação, enquanto o real objetivo deveria ser a atualização e o aprofundamento de conhecimentos novos, aprimoramento e inovações, tanto em questões da vida geral, quanto no âmbito da área de atuação.

Alferes e Mainardes (2011) acreditam que

para que tal situação seja transformada, é necessário que se estabeleçam programas de formação continuada de professores, como meio de fomentar a produção de intelectuais críticos, de aprimorar seus conhecimentos teóricos e estimular sua reflexão crítica a partir de seu contexto da prática (p.10).

Assim, a proposta de formação continuada poderá alcançar seu principal objetivo, que deve ser a possibilidade de os professores confrontarem e repensarem os seus referenciais e práticas pedagógicas, fundamentados em uma concepção crítica, de modo a melhorar seu exercício docente, além de fortalecer o reconhecimento de sua profissionalidade ${ }^{3}$. Ferreira (2008) acredita que uma perspectiva crítica da formação continuada precisa acontecer em um ambiente que tenha comprometimento com o desenvolvimento da atuação docente, articulando políticas sociais à prática pedagógica e às ações junto aos alunos, e não reproduzam uma visão meramente mercadológica.

Alferes e Mainardes (2011) afirmam que a formação continuada precisa valorizar o saber teórico, assim como fazer a instrumentalização dos professores para que eles possam implementar as práticas pedagógicas com o intuito de garantir a internalização do conhecimento por todos os discentes.

Saviani (2008), por sua vez, faz crítica à formação de professores, afirmando que por vezes ela é pensada de forma estratégica, somente para atender ao mercado, sem se pensar em como contribuir para melhorias do sistema educacional do país. Com relação ao pedagogo, por exemplo, considera que esse profissional foi taxado de generalista, pois "se procurou privilegiar a formação de técnicos por meio das habilitações com funções supostamente bem específicas 3 Para Guimarães (2006), a profis
é inerente ao trabalho pedagógico-didático. 
no âmbito das escolas e sistemas de ensino que configurariam um mercado de trabalho" (p.51). Nesse contexto, a formação do pedagogo está subordinada à produtividade social, buscando atender às demandas do mercado de trabalho e à indústria cultural', o que, para Adorno (1999), "impede a formação de indivíduos autônomos, independentes, capazes de julgar e de decidir conscientemente" (p. 295).

Baseado em uma perspectiva marxista, Frigotto (2008) analisa que "a educação dos diferentes grupos sociais de trabalhadores deve dar-se a fim de habilitá-los técnica, social e ideologicamente para o trabalho. Trata-se de subordinar a função social da educação de forma controlada para responder às demandas do capital" (p. 26).

Coêlho e Guimarães (2012) afirmam que a educação é considerada pela sociedade e pelo Estado (MEC) conforme a lógica da quantidade de produto e resultados da produtividade, atendendo assim a lógica do capital, sem se pensar na qualidade do ensino ofertado. Entretanto, os autores acreditam que o principal objetivo da formação não pode ser a preservação da situação atual dos indivíduos, ou mesmo da sociedade, mas precisa ser um projeto de melhoria da sociedade em geral e mesmo da educação, embasado na liberdade, igualdade, justiça e fraternidade.

Esses autores também acreditam que, no que tange à concepção de formação de professores que atenda somente aos interesses do "mercado", a tendência é a de perpetuar aquilo que é tido como "verdade". Por exemplo, se os princípios da formação forem baseados na lógica do capitalismo para o atendimento ao mercado de trabalho, as suas práticas como docentes transmitirão os ideais do capitalismo, contribuindo para a formação de cidadãos consumidores de informações, o que "limita capacidades e saberes e empobrece os horizontes culturais e humanos dos educandos, além de deixar jovens e adultos vulneráveis no mundo do trabalho" (CÔELHO e GUIMARÃES, 2012, p. 10). Para os autores,

\footnotetext{
4 "se trata de uma transmissão programada e intencional de necessidades, costumes, vontades, maneiras etc., para universalizar os pensamentos e as vontades da população, para manipulá-las a respeito do que comprar, do que querer, do que fazer e de como agir.” (DONATO, 2008).
} 
À medida que se circunscreve à esfera do imediato, deixa-se banalizar e empobrecer, esquece a complexidade e o caráter conflituoso e contraditório da sociedade e das instituições, a educação, a escola se desinteressam pela interrogação de seu sentido e razão de ser e se torna incapaz de motivar e instigar o pensamento e a criação. E assim, corre o risco de contribuir para manter a sociedade e as instituições, apenas fazendo-as funcionar, ao invés de ajudar os indivíduos, a sociedade e a humanidade a buscarem a gênese e o sentido dessas contradições e conflitos, bem como a pensá-los, a compreendê-los e a manterem uma convivência respeitosa com os que têm concepções diferentes, mesmo preservando suas convicções” (p. 10).

Assim, a formação continuada tem como principal função contribuir para o desenvolvimento pessoal e profissional do educador, no sentido de instigar o pensamento crítico e a autonomia docente para lidar com a realidade vivida dentro do espaço escolar. Além disso, deve propiciar as ferramentas teóricas e metodológicas para enfrentar e buscar as soluções para os muitos desafios impostos pelos processos de ensino, aprendizagem, gestão e organização do trabalho escolar, inseridos numa sociedade em constante transformação.

\section{O CENTRO DE FORMAÇÃO DE PROFESSORES NO MUNICÍPIO DE GOIÂNIA}

Para compreender a relação entre a formação continuada e as políticas públicas de avaliação em larga escala, foram analisados documentos como a Lei de Diretrizes e Bases da Educação (BRASIL, 1996), a legislação relativa à instituição e implementação do IDEB, as Diretrizes Curriculares da Formação Inicial e Continuada (BRASIL, 2015) e a Política de Formação Continuada em Rede (GOIÂNIA, 2013) do município de Goiânia. A fim de compreender o contexto no qual os cursistas estão inseridos, foi necessário conhecer e analisar a Gerência de Formação dos Profissionais (GERFOR) da SME, bem como a formação continuada oferecida pela rede do município de Goiânia. 


\section{GERÊNCIA DE FORMAÇÃO DOS PROFISSIONAIS DA SME}

O Centro de Formação de Professores ${ }^{5}$, hoje nomeado Gerência de Formação dos Profissionais da SME (GERFOR), foi criado em fevereiro de 1999, com o objetivo de proporcionar atividades para aperfeiçoar a prática dos profissionais da educação da Rede Municipal de Ensino. Antes da criação do Centro de Formação dos profissionais da Rede Municipal de Educação de Goiânia, a formação continuada se dava por meio de palestras, seminários, simpósios, congressos, encontros, cursos em parceiras com as IES, bem como pelo acompanhamento das equipes técnicas da SME, o que está coerente com as DCN (BRASIL, 2015), que afirmam, no inciso primeiro do Art. 17, que a formação continuada deve ser pautada na oferta de atividades que buscam a formação e cursos de atualização, extensão, aperfeiçoamento, especialização, mestrado e doutorado que agreguem novos saberes e práticas, articulados às políticas e gestão da educação, à área de atuação do profissional e às instituições de educação básica, em suas diferentes etapas e modalidades.

No município de Goiânia, a Gerência de Formação dos Profissionais da Educação é responsável pela formação continuada dos profissionais da rede. Segundo a coordenadora da GERFOR, são ofertados em média 50 cursos por ano, para cerca de 10.000 profissionais, desde a sua criação. A definição do público alvo para os cursos a serem oferecidos considera o perfil dos profissionais da RME (Rede Municipal de Educação) aos quais se destinam, levando em conta a função exercida pelos profissionais: apoios técnicos-professores, diretores, coordenadores, professores regentes e administrativos.

No caso dos cursos opcionais, as inscrições são realizadas conforme quantitativo de vagas disponibilizadas. Para os cursos que requerem representantes das instituições, quando obrigatórios, são realizadas pelo coletivo das próprias escolas ou instituições. A GERFOR conta com um blog, por meio do qual são realizadas as inscrições para as ações formativas (www.cefpe.blogspot.com.br).

A divulgação das ações formativas acontece via ofício às Instituições Educacionais, por meio das Coordenadorias Regionais de Educação (CRE) e publicadas no blog da gerência. Cabe à direção e à coordenação pedagógica das Instituições Educacionais a responsabilidade pela socialização do ofício que encaminha a divulgação de ação formativa oferecida pela GERFOR. Quanto

5 A transição de Centro de Formação para Gerência de Formação, ocorre com Decreto № 1981 , DE 08 de julho de 2016 que aprova o Regimento Interno da Secretaria Municipal de Educação e Esporte, no Capítulo III "Da organização estrutural”. O Art. 6 estabelece que "Integram a estrutura organizacional e administrativa da SME, nos termos do item 13, do Anexo I, da Lei Complementar $n^{\circ}$ 276/2015, com alterações pela Lei Complementar n 293, de 30 de junho de 2016” (p.05), nos itens 4. Superintendência Pedagógica e de Esportes e 4.1. Diretoria Pedagógica, na qual a Gerência de Formação de Profissionais da SME está inserida. 
à quantidade de vagas a serem disponibilizadas para cada ação formativa, a definição é feita pela própria Gerência, sempre de acordo com o tema proposto e as condições para efetivá-la.

Em 2018 a Gerência contava com 28 profissionais efetivos na formação continuada, que, segundo resposta prestada ao questionário de pesquisa pela coordenação, tem o seguinte perfil acadêmico-profissional:

ter domínio teórico e metodológico das Propostas Pedagógicas da RME; conhecer a dinâmica interna de trabalho da RME; conhecer e compreender a Política de Formação Continuada em Rede; ter domínio dos pressupostos da Teoria Histórico-cultural; demonstrar uma postura investigativa e crítica; ter domínio do conhecimento científico, ético, estético e político concernente à área de trabalho em que atuará; ter capacidade de trabalhar de forma interdisciplinar e coletiva (coordenação da GERFOR, 2019).

De acordo com a coordenadora da gerência, para atuarem na formação continuada, os profissionais da RME precisam ser indicados pelo Gabinete da SME e pela Superintendência Pedagógica e de Esportes, Diretoria Pedagógica. A seleção é feita por meio de entrevista com a equipe gestora da GERFOR. Quanto aos formadores que são convidados externos, atuam mediante o estabelecimento de convênios e/ou parcerias com outras instituições. Nesse caso, não há seleção, uma vez que trabalham nas instituições parceiras.

Com relação à formação dos formadores da Gerência de Formação, a coordenadora informou que eles se formam no exercício de suas funções com participações em cursos, palestras, fóruns, encontros, seminários, grupos de estudo, simpósios, debates internos, dentre outros. A equipe de formadores das ações propostas, juntamente com as coordenadoras e gerências, são os responsáveis por definir os planejamentos dos cursos a serem ofertados (conteúdos, objetivos, metodologia, materiais/recursos e avaliação).

Quanto ao Plano de Trabalho e os temas abordados pela GERFOR, são de responsabilidade da Superintendência Pedagógica e de Esportes, Gerências da Diretoria Pedagógica, Coordenadorias Regionais de Educação e também das Instituições Educacionais, definidos, em geral, após consulta aos responsáveis pelas instituições por meio do diálogo estabelecido com as diferentes instâncias da SME e com os profissionais da RME. Quando questionada sobre a avaliação de desempenho dos cursistas, a coordenadora disse que 
se dá por meio da participação efetiva nos estudos, na realização das atividades propostas, na análise, síntese e apresentação de uma proposta de intervenção pedagógica a partir dos dados da avaliação. Para ter direito à certificação o cursista deve ter frequência mínima de $75 \%$ (setenta e cinco por cento) e nota igual ou superior a 70 (setenta), de acordo com o Estatuto dos Servidores do Magistério Público do Município de Goiânia - Lei no 091, de 26 de junho de 2000. A ação formativa é avaliada pelos cursistas mediante instrumento elaborado pela GERFOR (coordenadora da GERFOR, 2019).

Ainda de acordo com a coordenadora, os cursos, quando obrigatórios, acontecem dentro do horário de trabalho e em turmas que atendam o quantitativo de profissionais convocados.

Atualmente, a formação continuada oferecida pelo município de Goiânia é regida pela Política de Formação Continuada em Rede (PFCR), a Proposta Político Pedagógica para a formação continuada dos profissionais da SME de Goiânia (GOIÂNIA, 2013), o até então Centro de Formação dos Profissionais da Educação (CFPE), agora GERFOR, sendo uma instância do Departamento Pedagógico (DEPE) que tem como responsabilidade propor, articular e implementar a Política de Formação Continuada em Rede. A PFCR (2013) ressalta que a formação continuada oferecida não se restringe aos professores, mas abrange todos os profissionais envolvidos na educação.

Nesse sentido, se faz necessário conhecer a concepção desse documento. Assim, a PFCR estabelece que por política de formação continuada compreendese "o conjunto de pressupostos políticos, epistemológicos e pedagógicos que orientam os saberes e práticas, considerando a unidade de todas as ações formativas empreendidas pela SME" (GOIÂNIA, 2013, p. 9).

Assim, a política anunciada dialoga coma Rede externa (Conselho Municipal de Educação, Agências Formadoras, Secretarias Municipais, Movimentos Sociais, Políticas Públicas, dentre outros), interna (entre os Departamentos e instâncias da SME), bem como com as instituições educacionais, a fim de qualificar e garantir a consecução das Propostas Político Pedagógicas da Educação Infantil, Ensino Fundamental, da Infância e da Adolescência e da Educação Fundamental de Adolescentes, Jovens e Adultos. Essa Política materializa-se por meio de Projetos Formativos e Ações Formativas.

O documento também ressalta que, tão logo seja aprovada a Política de Formação Continuada em Rede pelo Conselho Municipal de Educação (CME), "não haverá necessidade de elaborar e encaminhar projetos de cursos isolados para serem desenvolvidos, uma vez que todos eles deverão partir dos pressupostos aqui defendidos e dos projetos formativos deles apreendidos" (GOIÂNIA, 2013, p. 9 e 10). 
Observa-se ainda que, na trajetória dos processos formativos, buscou-se possibilitar a problematização da experiência docente imediata, com o intuito de mediá-la com eixos epistemológicos das diversas áreas de conhecimento que são fundamentais na educação. Desse modo,

Essa intencionalidade resultou no afastamento de fórmulas prescritivas, assumindo, como princípio e método, os fundamentos epistemológicos do conhecimento e suas possibilidades metodológicas. Essa perspectiva formativa não se limita ao "saber fazer" contingente e circunscrito às narrativas e relatos de experiência, mas antes, envolve a articulação entre pressupostos pedagógicos e a realidade das instituições educacionais. (Ibid., p. 06).

Observa-se que esse princípio converge para o que propõe Nóvoa (1991), para quem a formação continuada precisa ser crítico reflexiva e não deve ficar no âmbito de aperfeiçoamento das práticas. É necessário que sejam fornecidos aos professores "os meios de um pensamento autônomo e que facilite as dinâmicas de autoformação participada, o que implica um investimento pessoal, um trabalho livre e criativo sobre os percursos e os projectos próprios, com vistas à construção de uma identidade profissional" (p. 25).

A PFCR (2013) expressa a compreensão da RME em considerar a formação continuada como um movimento contínuo e dialético, que possibilita aos profissionais da educação aspectos necessários para a reflexão da práxis pedagógica nos diferentes espaços educativos da rede escolar. Busca, assim, um constante diálogo com as políticas públicas educacionais nacionais e locais que associam a formação continuada para os profissionais da educação com a qualidade da educação básica no Brasil.

Em consonância com a LDB, as ações formativas promovidas pela SME assumem a formação sólida do profissional da educação, a valorização e profissionalização como pontos primordiais, reafirmando a importância da formação para qualificação do trabalho nas instituições educacionais e para a progressão na carreira docente e na administrativa, em consonância, portanto, com o Estatuto dos Servidores do Magistério Público do Município de Goiânia (Lei Complementar n ${ }^{\circ}$ 091, de 26 de junho de 2000) e Planos de Cargos, Carreiras e Vencimentos dos Trabalhadores Administrativos da Educação do Município de Goiânia (Lei n 9128 , de 29 de dezembro de 2011). (Ibid., p. 08).

A PFCR considera a formação continuada como elemento que contribui para a consolidação da identidade profissional, e então “o foco das atenções deslocase do quanto, do que e do como se acumula na formação para a problematização do sentido e do porquê se produz um conhecimento histórico e socialmente determinado" (p. 8). Dessa forma, para contribuir com a qualificação do saberfazer dos profissionais da educação, busca privilegiar a prática investigativa e 
problematizadora da realidade "tendo em vista uma formação crítica e propositiva que interroga, questiona e que, coletivamente, promove mudanças qualitativas nas ações cotidianas" (p. 9).

Em decorrência desses fatores, a PFCR está em consonância com a Rede Nacional de Formação Continuada de Professores da Educação Básica ${ }^{6}$ (BRASIL, 2005), quando estabelece que "a formação do educador deve ser permanente e não apenas pontual, [pois] a formação continuada não é correção de um curso por ventura precário, mas necessária para a reflexão permanente do professor" (p. 5, acréscimos nossos), buscando sempre a melhoria na qualidade do ensino ofertado pela educação.

A PFCR também atende ao que estabelece o Conselho Nacional de Educação (CNE), em sua resolução de $\mathrm{N}^{\circ}$ 2, de 1 de julho de 2015, que formaliza as Diretrizes Curriculares Nacionais para a formação inicial em nível superior, bem como a formação continuada. No artigo 16 do capítulo VI, intitulado " $\mathrm{Da}$ formação continuada dos profissionais do magistério", descreve que

a formação continuada compreende dimensões coletivas, organizacionais e profissionais, bem como o repensar do processo pedagógico, dos saberes e valores, e envolve atividades de extensão, grupos de estudos, reuniões pedagógicas, cursos, programas e ações para além da formação mínima exigida ao exercício do magistério na educação básica, tendo como principal finalidade a reflexão sobre a prática educacional e a busca de aperfeiçoamento técnico, pedagógico, ético e político do profissional docente (Ibid., p. 13).

A PFCR estabelece que os Projetos de Ações Formativas, obrigatoriamente, devem estar sintonizados com a legislação educacional Diretrizes Curriculares Nacionais para Educação Básica, O Plano Nacional Educacional (PNE), Plano Municipal de Educação (PME) e os Regulamentos e Portarias em âmbito nacional e local. Em razão disso, os profissionais formadores precisam conhecer os documentos que pautam cada nível e modalidade, para que seja possível construírem ações interdisciplinares e consolidar uma Política de Formação Continuada em Rede, o que pressupõe "qualificar os processos de ensino e aprendizagem em todas as etapas e modalidades que implicam ações, opções e políticas estratégicas na RME, tendo em vista a garantia do direito à aprendizagem e à formação humana de todos os sujeitos que participam do processo educativo" (Ibid., p. 12).

6 Criada em 2004, objetivando a contribuição para a melhoria da qualidade da formação dos professores e alunos. Essa rede tem como público alvo os professores de educação básica da rede pública de ensino. 
Do ponto de vista epistemológico, a Política de Formação Continuada da SME reafirma os

pressupostos que norteiam a aprendizagem e o desenvolvimento humano em uma Perspectiva Histórico-cultural e os Fundamentos do Materialismo Histórico Dialético, como método de estudo e compreensão da realidade. É deste referencial epistêmico que se parte para a compreensão do sentido político e pedagógico que articula as ações formativas em Rede (Ibid., p. 14).

O documento destaca a importância da estreita relação que deve existir entre a Política de Formação e as políticas públicas educacionais para que se possa garantir os direitos sociais, humanos e civis.

A PFCR, que tem sua materialização pautada em projetos e ações formativas, deve partir da dialeticidade, da historicidade e da identidade profissional. Para a efetivação da PFCR, é necessário considerar os pressupostos pedagógicos que devem conduzir essa política, tais como considerar a formação como um processo contínuo, capaz de agregar os saberes advindos da formação inicial com aqueles adquiridos no exercício da profissão.

Segundo estabelece a PFCR, para que se efetive a Política de Formação Continuada em Rede, é necessário considerar os pressupostos pedagógicos que irão subsidiar a forma que esta Política será conduzida, tais como: a formação como processo contínuo, que articule saberes da formação inicial com os obtidos no exercício da profissão; os saberes da formação - articular o conhecimento científico, o conhecimento pedagógico e o conhecimento sobre a Rede, ou seja, aqueles que corroboram com o fortalecimento da identidade profissional, bem como os que perpetuam as práticas consagradas culturalmente, por serem significativos; a interdisciplinaridade, considerada como processo e resultado de estudo e produção de conhecimento sistematizado, pois trata, questiona, interroga, estranha e valida o conhecimento.

A PFCR explicita preocupação com a formação dos formadores da GEFOR, sendo estes considerados "importantes sujeitos na consolidação desta Política” (p.32). Assim, estabelece que cabe ao Departamento Pedagógico (DEPE) e à Gerência de Formação a priorização de temas como "a educação como política pública, a Teoria Histórico Cultural e o Materialismo Histórico-dialético, como fundamentos epistemológicos, a interdisciplinaridade, dentre outros” (p.31-32).

Destaca a importância da articulação e parceria com as universidades locais para "oferta de grupos de estudos para os professores/formadores do CEFPE, como forma de ampliar e fortalecer o debate acadêmico, bem como 
assessorar o CEFPE na condução dos estudos da Política de Formação" (p.32). Enfatiza também a importância de os formadores participarem de momento externos, como apresentações, representação e eventos externos à SME.

\section{CONSIDERAÇÕES FINAIS}

No presente estudo buscou-se analisar as políticas públicas que têm subsidiado a formação continuada de professores no Brasil entre os anos de 2008 a 2016, identificando também os fundamentos históricos, teóricos e metodológicos que sustentam a formação continuada dos professores na Gerência de Formação dos Profissionais da SME, por meio de pesquisa bibliográfica e documental.

A formação continuada dos profissionais da educação de Goiânia é de responsabilidade da GEFOR, antes nomeada Centro de Formação de Professores, desde 1999, com o objetivo de proporcionar atividades para aperfeiçoar a prática dos profissionais da educação da Rede Municipal de Ensino.

De acordo com os resultados deste estudo, a formação continuada da rede municipal de Goiânia, que acontece via GERFOR, tem sido realizada com a perspectiva de contribuir com a consolidação da identidade profissional dos professores e demais profissionais da rede, bem como com a qualidade do ensino a ser ofertado, privilegiando uma prática investigativa e problematizadora da realidade. Os cursos são organizados a partir de temas sugeridos pelos professores, objetivando discutir o dia a dia no espaço escolar com vistas a possibilitar a melhoria dos processos de ensino e aprendizagem.

Nesse cenário, a formação continuada se constitui como uma política pública que propicia a atualização do profissional já em exercício da função. Entretanto, a formação também é imersa no contexto de influência neoliberal, no qual a formação continuada é vista como uma oportunidade para atender às demandas e necessidades imediatas oriundas do "mercado de trabalho".

Em relação às avaliações nacionais e em larga escala, este estudo mostrou que as políticas públicas que as subsidiam, as justificam como sendo indutoras de qualidade do ensino, na medida em que possibilita identificar as lacunas no desenvolvimento dos estudantes. Quanto ao resultado da pesquisa no âmbito da GERFOR, foram analisados documentos e dados coletados divididos em três categorias para análise: Gerência de Formação dos Profissionais da SME; o processo de formação continuada no município de Goiânia; a relação das políticas de avaliações externas (Saeb/Ideb) e a formação continuada no município de Goiânia. 
Por fim, tendo em vista que as políticas para formação continuada: abrangem cursos de curta ou longa duração; promovem a atualização, o desenvolvimento e aprofundamento profissional constante dos profissionais docentes; buscam atender às necessidades recorrentes da prática educacional; acompanham o desenvolvimento da legislação educacional e promovem a atualização permanente dos conhecimentos e saberes da docência, conclui-se que a GERFOR tem alcançado os seus objetivos de modo a subsidiar as melhorias das práticas dentro do ambiente escolar. Entretanto, embora haja indícios de que os resultados do IDEB possam influenciar no planejamento dos cursos ofertados pela GERFOR, o presente estudo é inconclusivo no que tange à esse aspecto, não nos permitindo afirmar que esse índice seja determinante dos currículos dos cursos ofertados no período estudado.

\section{REFERENNCIAS}

ADORNO, T. W. Textos escolhidos. São Paulo: Nova Cultural, 1999.

ALFERES, M. A.; MAINARDES, J. A. FORMAÇÃO CONTINUADA DE PROFESSORES NO BRASIL. In: Seminário de Pesquisa do PPE. Universidade Estadual de Maringá: 2011. Disponível em: http://www.ppe.uem. br/publicacoes/seminario_ppe_2011/pdf/1/001.pdf. Acesso em: abril de 2018.

ALONSO, M. O trabalho docente: teoria \& prática. São Paulo: Pioneira, 1999.

ANDALÓ, C. S. de A. Fala, professora!: repensando o aperfeiçoamento docente. Petrópolis, RJ: Vozes, 1995.

ASSIS, L. M.; LIMA, D. C. B. P. Editorial. Atordoado eu permaneço atento. Revista Brasileira de Política e Administração da Educação, v. 34, n. 02, p. 329-345, mai./ago., 2018.

ASSIS, L. M. de; AMARAL, N. C. Avaliação da Educação: Por um sistema nacional. Revista Retratos da Escola, Brasília, v. 7, n. 12, p. 27-48, jan./jun. 2013. Disponível em: http://retratosdaescola.emnuvens.com.br/rde/article/ viewFile/258/436. Acesso em: jan. 2019.

ASSIS, L. M. de. As condições de trabalho de professores da educação básica em Goiás. In: OLIVEIRA, D. A., VIEIRA, L. F. Trabalho docente na educação básica em Goiás. Belo Horizonte, MG: Fino Traço, 2012. p. 115-132. 
ASSIS-PETERSON, A. A.; SILVA, E. M. N. "Não tenho estoques de sonhos para me manter em pé": construção de identidades de uma professora de inglês. In: BARROS, S. M.; ASSIS-PETERSON, A. A. (Org.). Formação crítica de professores de línguas: desejos e possibilidades. São Carlos, SP: Pedro \& João Editores, 2010. p. 145-174.

BOURDIEU, Pierre. A distinção: crítica social do julgamento. Porto Alegre: Zouk, 2011.

BRASIL. Ministério da educação conselho nacional de educação conselho pleno. Resolução no 2, de $1^{\circ}$ de julho de 2015. In: Diário Oficial da União, Brasília, 2 de julho de 2015 - Seção 1 - pp. 8-12. Disponível em: http://pronacampo.mec. gov.br/images/pdf/res_cne_cp_02_03072015.pdf. Acesso em: junho de 2016.

BRASIL. Lei 5.692, de 11 de agosto de 1971. Fixa Diretrizes e Bases para o ensino de $1^{\circ}$ e $2^{\circ}$ graus, e dá outras providências. Brasília, DF: 1971. Disponível em: Acesso em 10 maio de 2017.

BRASIL. Lei de Diretrizes e Bases da Educação Nacional. 5a Edição, [1996] 2010. Biblioteca Digital da Câmera dos Deputados. Disponível em: http:// bd.camara.gov.br/bd/bitstream/handle/bdcamara/2762/ldb_5ed.pdf. Acesso em: outubro de 2011.

BRASIL. Ministério da Educação e do Desporto. Diretrizes curriculares nacionais para a educação infantil. Câmara de Educação Básica do Conselho Nacional de Educação. Brasília: 1998.

BRASIL. Portaria Normativa n. 14, de 21 de maio de 2010. Institui o Exame Nacional de Ingresso na Carreira Docente. Diário Oficial da União, seção 1, n.24, f. 11, 24 maio 2010.

BRASIL. Ministério da Educação. Lei de Diretrizes e Bases da Educação. Brasília, DF, 1996. Disponível em: http://portal.mec.gov.br/index. php?option $=$ com_content\&view $=$ article $\&$ id $=12907$ :legislacoes $\&$ catid $=70:$ legisl acoes. Acesso em: junho de 2016. 
BRASIL. Parecer CNE/CP 9/2001. Homologado em 17/01/2002. MINISTÉRIO DA EDUCAÇÃO. Conselho Nacional de Educação. Disponível em: http://portal.mec.gov.br/cne/arquivos/pdf/009.pdf. Acesso em: junho de 2016.

BRASIL, Ministério da Educação. Projeto de Lei do Plano Nacional de Educação (PNE 2011-2020): projeto em tramitação no Congresso Nacional PL no 8.035/2010. Brasília, DF: Edições Câmera, 2011.

BRASIL. Lei da Reforma do Ensino de $1^{\circ}$ e $2^{\circ}$ graus. Lei ${ }^{\circ} .5 .692 / 71$, de 11 de agosto de 1971. Fixa Diretrizes e Bases para o ensino de $1^{\circ}$ e $2^{\circ}$ graus, e dá outras providências. In Política e Educação no Brasil. 5. ed. Campinas: Autores Associados, 2002.

BRASIL, Ministério da Educação/SEB. Rede Nacional de Formação Continuada de Professores da Educação Básica - Orientações Gerais, Brasília, 2005.

CHIMENTÃO, L. K. O significado da formação continuada docente. $4^{\circ}$ CONPEF - Congresso Norte Paranaense de Educação Física Escolar, 2009. Disponível em: http://www.uel.br/eventos/conpef/conpef4/trabalhos/ comunicacaooralartigo/artigocomoral2.pdf. Acesso em: abril de 2016.

COÊLHO, I. M; GUIMARÃES, G. Educação, escola e formação. Goiânia, 2012. Disponível em: https://repositorio.bc.ufg.br/xmlui/handle/ri/487. Acesso em: janeiro de 2017.

DIAS SOBRINHO, J. Campo e caminhos da avaliação: a avaliação da educação superior no Brasil. In: FREITAS, L. C. (org.). Avaliação. Construindo o campo e a crítica. Florianópolis: Insular, 2013. v. 1. p. 13-62.

DONATO V. Logística Verde: Uma abordagem sócio-ambiental, Rio de Janeiro, Editora Ciência Moderna, 2008.

FERREIRA, N. S. C. A gestão enquanto instrumento para a construção e qualificação da educação. Disponível em: http://portal.mec.gov.br/seb/ arquivos/pdf/gestao.pdf. Acesso em: 07 jul. de 2008. 
FERREIRA, N. S. C. Gestão democrática da educação: ressignificando conceitos e possibilidades. In: FERREIRA, Naura Syria Carapeto; AGUIAR, Márcia Ângela da S. (Org.). Gestão da Educação - Impasses, perspectivas e compromissos. São Paulo: Cortez, p. 295-316, 2008.

FREIRE, P. Pedagogia da Autonomia: saberes necessários à prática educativa. São Paulo: Paz e Terra, 2001.

FREITAS, D. N. T. de. Avaliação da Educação Básica no Brasil: características e pressupostos. In: BAUER, A.; GATTTI, B. A.; TAVARES, M. R. (orgs.) Ciclo de Debates: vinte e cinco anos de avaliação de sistemas educacionais no Brasil, origens e pressupostos. Florianópolis: Editora Insular, 2013, p.70-96.

FRIGOTTO, Gaudêncio. O enfoque da dialética materialista histórica na pesquisa educacional. São Paulo: Cortez, 2008.

GATTI, B. A. Análise das politicas públicas para a formação continuada no Brasil, na última década. Revista Brasileira de Educação. Campinas: Autores Associados. v.13, n.37, p. 57-70, 2008.

GATTTI, B. A. Formação continuada de professores: a questão psicossocial. Cadernos de Pesquisa. [online] 2003 n. 119. Disponível em:http://www.scielo. br/scielo.php?script $=$ sci_arttext\&pid=S0100-15742003000200010\&lng=pt\&nr $\mathrm{m}=$ iso. Acesso em: julho de 2016.

GATTT, B. A. Possibilidades e Fundamentos de avaliações em larga escala: primórdios e perspectivas contemporâneas. In: BAUER, Adriana; GATTTI, Bernadete A.; TAVARES, Marialva R. (Orgs.). Ciclo de debates: vinte e cinco anos de avaliação de sistemas educacionais no Brasil, origens e pressupostos. Florianópolis: Editora Insular, 2013, p.47-69.

GOIÂNIA. Secretaria Municipal de Educação e Esportes. Gerência de Formação dos Profissionais da Educação. Política de Formação Continuada em Rede: Proposta políticopedagógica para formação continuada dos profissionais da Secretaria Municipal de Educação e Esportes de Goiânia. Out.2013. 
GUIMARÃES, V. S. A socialização profissional e profissionalização docente: um estudo baseado no professor recém-ingresso na profissão. In.: GUIMARÃES, V. S. (Org.). Formar para o mercado ou para a autonomia? O papel da Universidade. Campinas: Papirus, 2006.

GUIMARÃES. V. S. Formação de professores: Saberes, identidades e profissão. Campinas, SP: Papirus, 2004.

IMBERNÓN, F. Formação docente e profissional: formar-se para a mudança e a incerteza. São Paulo: Cortez, 2001.

JANELA, A. A. Avaliação Educacional: regulação e emancipação. São Paulo: Cortez, 2000, p.13-51.

LIBÂNEO, J. C. Organização e gestão da escola: teoria e prática. 5. ed. Goiânia: MF Livros, 2008.

LUCKESI, C. C. Avaliação da aprendizagem escolar. 21 ed. São Paulo: Cortez, 2010.

NÓVOA, A..A formação contínua de professores: realidades e perspectivas. Aveiro: Universidade de Aveiro, 1991.

PIMENTA, S. G.; GHEDIN, E. (Orgs.). Professor reflexivo no Brasil: gênese e crítica de um conceito. São Paulo: Cortez, 2002.

RIBAS, M. H. Construindo a competência: processo de formação de professores. São Paulo: Olho d’Água, 2000.

SAVIANI, D. Pedagogia histórico-crítica: primeiras aproximações. 10 ed. Campinas: Autores Associados, 2008.

SILVA, C. S. R. da; FRADE, I. C. A. da. Formação de professores em serviço. Presença Pedagógica, Belo Horizonte, v. 3, n. 13, 1997.

SOARES, K. C. D. Trabalho docente e conhecimento. 2008. Tese (Doutorado em Educação) - Centro de Ciências da Educação Universidade Federal de Santa Catarina, 2008. 
SOUZA, Jessé. A elite do atraso. Rio de Janeiro: LeYa, 2017.

VEIGA, I P.A. Escola: Espaço do Projeto Político-Pedagógico. 7. ed. Campinas, SP: Papirus.1998.

\section{Sarah Rizzia Campos Luiz}

Pedagoga, Especialista Em Docência Universitária, Mestre Em Educação Pelo Programa De Pós Graduação Em Educação Da Faculdade De Educação Na Universidade Federal De Goiás. E-mail: sarahrizziaclm@hotmail.com

\section{Lúcia Maria Assis}

Professora Coordenadora do Programa de Pós-Graduação em Educação da Faculdade de Educação da Universidade Federal de Goiás (UFG). Doutora em Educação pela UFG. E-mail: luciamariadeassis@gmail.com 